\title{
PENGGUNAAN BAHASA INDONESIA DALAM PROSES KOMUNIKASI PERSUASIF DAN ADAPTASI BUDAYA IMIGRAN ANAK TANPA PENDAMPING DI KOTA MEDAN
}

oleh:

\author{
Christin Agustina Purba ${ }^{1}$ (christinpurba@unprimdn.ac.id) \\ Nanda Dwi Astri² (nandadwiastri@unprimdn.ac.id)
}

\begin{abstract}
ABSTRAK-Bahasa merupakan aspek yang begitu penting dalam kehidupan bermasyarakat. Salah satu fungsi dari bahasa adalah sebagai alat komunikasi. Bahasa berperan penting dalam komunikasi antar negara dengan berbagai kebudayaan. Banyaknya jumlah imigran yang berada di Indonesia serta keberadaan mereka yang berada dibawah pengawasan petugas petugas pendampingan, namun sebagian besar imigran ini tidaklah memahami bahasa Inggris ataupun bahasa Indonesia. Meskipun negara Indonesia bukanlah menjadi tujuan utama para imigran ini. Indonesia hanyalah merupakan negara transit sementara mereka dengan harapan akan dimudahkan dalam proses reshuttement ke negara ketiga (tujuan). Proses adaptasi sempurna atau assimilation tidak berjalan karena migran anak dengan lingkungan masyarakat di luar DCH, proses yang gagal dalam proses komunikasi persuasif antara pekerja sosial dengan anak. Adaptasi, sejauh ini, tidak menunjukkan tanda-tanda konflik besar.
\end{abstract}

Kata Kunci: bahasa Indonesia, persuasif, adaptasi budaya

\section{A. Pendahuluan}

Banyaknya jumlah imigran yang berada di Indonesia serta keberadaan mereka yang berada dibawah pengawasan petugas petugas pendampingan, namun sebagian besar imigran ini tidaklah memahami bahasa Inggris ataupun bahasa Indonesia. Sehingga fenomena inilah yang menjadi salah satu faktor dalam penelitian ini, dimana ingin melihat dan menggambarkan bagaimana penggunaan bahasa Indonesia sebagai bahasa dalam proses komunikasi persuasif oleh imigran anak tanpa pendamping yang berada di kota medan.Untuk memahami satu dengan yang lainnya dalam proses komunikasi diperlukan peran bahasa.

Bahasa berperan penting dalam komunikasi antar negara dengan berbagai kebudayaan. Sebuah komunitas dengan beragam bahasa induk akan menyulitkan proses komunikasi. Bahasa merupakan aspek yang begitu penting dalam kehidupan bermasyarakat. Salah satu fungsi dari bahasa adalah sebagai alat komunikasi. Untuk memahami satu sama lain dalam proses komunikasi diperlukan pemahaman yang sama dalam bahasa yang digunakan.

Kesatuan bahasa nantinya akan memudahkan setiap orang dalam berinteraksi, Oleh sebab itu, kesatuan bahasa saat ini merupakan posisi vital dan harus.Sebagai negara yang memiliki posisi strategis dalam pergaulan internasional, baik dari geografis maupun potensi sumber daya alam dan sumber daya manusia yang mengakibatkan arus lalu lintas orang masuk dan keluar wilayah Indonesia mudah dan semakin meningkat. Tidak terkecuali negara Indonesia menjadi tujuan dan sasaran oleh para imigran pencari suaka dari berbagai negara di dunia.sehingga fenomena inilah yang 
menjadi salah satu faktor dalam penelitian ini, dimana ingin melihat dan menggambarkan bagaimana penggunaan bahasa Indonesia sebagai bahasa dalam proses komunikasi persuasif oleh imigran anak tanpa pendamping yang berada di kota medan.

Adapun tujuan dari penelitian ini :

1. Untuk mengetahui bagaimana bahasa Indonesia berperean dalam proses komunikasi persuasif yang dilakukan oleh imigran anak tanpa pendamping yang berada di dalam akomodasi khusus migran anak.

2. Untuk mengetahui apakah ada hambatandalam proses adaptasi budaya imigran anak tanpa pendamping terhadap lingkungan yang berbeda dengan daerah tempat asal mereka.

Menurut Owen dalam Setiawan (2006:1), "bahasa adalah kode yang diterima secara sosial atau sistem konvensional untuk menyampaikan konsep melalui kegunaan simbol-simbol yang dikehendaki dan kombinasi simbol-simbol yang diatur oleh ketentuan". Fungsi bahasa menurut Abidin, dkk (2010:3) menjelaskan bahwa fungsi utama bahasa adalah sebagai media komunikasi, dalam berkomunikasi sehari-hari, salah satu alat yang paling sering digunakan adalah bahasa, baik bahasa lisan maupun bahasa tulis. Bahasa sebagai alat ekspresi diri dan sebagai alat komunikasi sekaligus pula merupakan alat untuk menunjukkan identitas diri.

Metode Penelitian

Penelitian ini merupakan penelitian kualitatif yang menggunakan paradigm konstruktivisme. Dalam mengkaji masalah ini penulis menggunakan teknik analisa datakualitatif. Penelitian ini akan menganalisa data primer dan data sekunder. Data primer dalam penelitian ini adalah data yang didapat dari wawancara mendalam terhadap narasumber.Kegiatan wawancara mendalam akan menggunakan pedoman wawancara sebagaiinstrumen pengumpulan data. Penelitian ini menggunakan analisis tematik, dan koding yangdigunakan dalam proses analisa data adalah open coding, axial coding dan selective coding.

\section{B. Metode Penelitian}

Analisis tematik digunakan sebagai dasar analisis penelitian kualitatif, agar memungkinkan peneliti untuk mendapatkan "pola" yang tidak nampak jelas dalam data dan tumpukaninformasi (Boyatzis, 1998 dalam Poerwandari, 2007). Dalam penelitian ini, pengolahan dan analisis data dimulai dengan mengorganisasi data temuan lapangan

Data primer dan sekunder disusun secara sistematis agar memperoleh kualitas data yang baik, mudah didokumentasikan dan mempermudah proses penyimpanan data dan analisa. objek analisis yang dipilih adalah Imigran anak tanpa pendamping yang berada di shelter penampungan-penampungan imigran anak di kota Medan. Imigran yang diwawancara adalah mereka yang berasal dari negara Afganistan, Somalian, Sudan dan Srilanka. Namun demikian, pengambilan data tidak hanya terbatas kepada migran ini saja, namun juga dari negara lain yang telah menggunakan bahasa Indonesia dalam komunikasi sehari-hari, dan juga pihak yang turut mengambil bagian dalam penanganan akomodasi anak migrananak, yang terlibat dalam komunikasi untuk beradaptasi. Objek penelitian adalah imigran anak tanpa pendamping yang berasal dari Negara Afganistan, Srilanka dan Somaliayang berada dipenampungan di kota Medan 


\section{Hasil Penelitian}

Berdasarkan hasil temuan data Laporan Program Pelayanan Pengungsi Bawah Umur Tanpa Wali di Dinsos Community House (DCH) di Shelter Wisma Virgo pada Tahun 2019 dapat diketahui bahwa anak migran yang berada dibawah guardianship DCH ada sebanyak 38 anak yang diawas sebanyak 12 petugas pelayanan di Dinsos Community House (DCH).Dinsos Community House mulai beroperasi sejak tahun 2013 dengan menampung 44 Migran anak dari 6 lokasi rumah detensi imigrasi (rudenim) yang tersebar di Indonesia. Fungsi Dinsos Communiy House menurut data laporan adalah menjadi fasilitator (perantara anak dengan keluarga/lembaga lain), Kuratif Rehabilitatif (mengembalikan dan menanamkan fungsi sosial bagi anak), Perlindungan, pusat informasi,memberikan akses terhadap pelayanan, resosialisasi dan pusat rujukan. Ditemukan beberapa hasil signifikan antara Lain:

1. Dari 38 orang anak yang berada di shelter virgo hanya 6 orang yang fasih berbahasa Inggris aktif, 4 orang bisa berbahasa Indonesia.

2. Pekerja sosial memfasilitasi pelajaran Bahasa Indonesia bagi migran yang berminatbelajar bahasa.

3. Migran juga mendapatkan homeschooling, tetapi ini lebih dikhususkan bagi merekayang sudah bisa berbahasa Inggris baik pasif ataupun aktif, dan mengerti bahasaIndonesia.

4. Migran merasa sangat kesulitan beradaptasi dengan lingkungan sekitar karena adabeberapa aturan yang mereka harus patuhi yang ada di shelter. Perbedaan budayayang sangat besar dengan Negara asal mereka sehingga mereka sangat berhti-hati dalam melakukan interaksi karena sangat takut akan adanya penolakan dari lingkungan. Latar belakang daerah asal serta trauma yang mereka dapatkan di masalalu sangat mempengaruhi mereka dalam berinteraksi.

5. Bagi migran yang bisa berbahasa Indonesia tidak kesulitan untuk beradaptasi dengan lingkungan sekitar tetapi sebaliknya migran yang tidak bisa berbahasa Indonesiahanya bisa berbahasa Ibu sedikit mengalami kesulitan dalam berinteraksi danberadaptasi.

6. Penggunaan bahasa Indonesia masih sangat minim dikalangan migran meskipunmereka telah berada di Indonesia Lebih dari 2 tahun.

Dari hasil data wawancara, dapat dikonstruksikan bahwa petugas di shelter khususnya pekerja sosial memberikan pesan persuasif kepada migran untuk dapat menyesuaikan diri/beradaptasi dengan budaya di Indonesia. Pada proses pemahaman pesan, persuader (Petugas lapangan) lebih mengutamakan budaya yang bertujuan agar Migran tidak berkonflik dengan masyarakat sekitar shelter dalam pemilihan tujuan pesan persuasifnya yang bertujuan agar Migran tidak berkonflik dengan masyarakat sekitar shelter dalam pemilihan tujuan pesan persuasifnya.Menghindari adanya pemicuan konflik dengan masyarakat lingkungan sekitar, petugas sosial bersepakat untuk membatasi sosialisasi Migran terhadap masyarakat luar (proses enculturation). Pada proses encoding, persuader (petugas di shelter) hanya menyampaikan melalui lisan. Berdasarkan hasil temuan data signifikan, terdapat noise dalam proses encoding yaitu kendala bahasa. Noise ini juga menjadi kendala 
dalam proses decoding oleh persuadee (Migran). Penggunaan bahasa dalam komunikasi yang terjadi di DCH lebih banyak mengandalkan bantuan bahasa isyarat atau penerjemah dari migran anak yang dapat berbahasa Indonesia atau bahasa asing lainnya. Pada proses evaluasi, Migran anak masih banyak menimbang isi pesan persuasif dari beberapa faktor. Bila disampaikan dengan bahasa yang dimengerti, migran anak cenderung menuruti pesan persuasif tersebut, selama tidak bertentangan dengan budaya asal mereka. Proses adaptasi sempurna atau assimilation tidak berjalan karena migran anak dengan lingkungan masyarakat di luar DCH, proses deculturation yang intens dari kelompok migran anak senegara maupun antara migran anak dengan kelompok imigran dewasa senegara lainnya, serta proses enculturation yang gagal dalam proses komunikasi persuasif antara pekerja sosial dengan anak. Status Luaran berisi status tercapainya luaran wajib yang dijanjikan.

\section{Kesimpulan}

Dari penelitian ini dapat disimpulkan bahwa 1) Proses komunikasi persuasif yang dilakukan oleh petugas sosial kepada UAM di DCH tidak berhasil karena faktor noise atau gangguan komunikasi, kurangnya pemahaman UAM terhadap masa depan mereka (yang mengakibatkan kurangnya motivasi UAM dalam mengembangkan diri) dan pekerja sosial tidak memiliki kewajiban untuk membuat UAM hingga berhasil diterima wawancara oleh negara dunia ketiga. 2) Pengunaan Bahasa Indonesia dalam Proses Komunikasi Persuasif oleh Migran Anak masih sangat Minim, karena bahasa Indonesia masih sangat minim digunakan dalam komunikasi sehari-hari ara migran.
3) Sebagian besar UAM masih belum bisa beradaptasi dengan budaya lokal di Medan, karena proses sosialisasi yang dibatasi oleh pekerja sosial dan petugas DCH karena menghindari kecemburuan sosial dan konflik dengan warga lingkungan sekitar diluar DCH. Proses adaptasi UAM terhadap budaya Indonesia UAM sendiri sedang berusaha untuk beradaptasi dengan UAM yang sekarang terdiri dari 4 negara yang berbeda, sejauh ini adaptasi tersebut sedang berjalan tanpa ada konflik besar.

\section{Daftar Pustaka}

Darman. 2010. Penegakan Peraturan Keimigrasian Dalam Mencegah Masuknya Imigran Illegal Ke Indonesia. Tesis Fakultas Ilmu Hukum Universitas SumateraUtara. Medan.

De Vito, Joseph A. 2011. Komunikasi Antar manusia, Edisi ke-5. Karisma Publishing Group. Jakarta.

Englund, Kate. 2011. Protecting the Human Rights of Unaccompanied Immigrant Minors. Advocates' Forum.

Ivashchenko, Kateryna. 2013. Eternal Return: Present-Day Problems Associated with Social Reintegration of Ukrainian Labor Migrants Arriving in Ukraine from EU(based on sociological research result). Research Report CARIM-East RR 2013/06.European Union.

Mulhadi. 2014. Pelanggaran Hukum Nasional Indonesia Yang Dilakukan Oleh Pengungsi Yang Berada di Wilayah Indonesia (Suatu Tinjauan 
Hukum Pengungsi Internasional). Makassar. Fakultas Hukum Universitas Hasanuddin.

Rajali. 2018. Laporan Program Pelayanan Pengungsi Bawah Umur Tanpa Wali di Dinsos Community House tahun di DCH Wisma Virgo Medan.

Sumirat, Soleh \& Suryana, Asep. 2014. Komunikasi Persuasif. Universitas Terbuka.Banten.
Utami, Lusia Savitri Setyo. Teori-Teori Adaptasi Antar Budaya. Jurnal Komunikasi Universitas Tarumanegara Vol. 7, No. 2, Desember 2015. Jakarta.

Wolcott, H.R. 1990. Qualitative inquiry in education: The continuing debate. The American Jurnal of Occupational Therapy. 